\title{
Correlation between Breastfeeding Duration and Motor Development in Children
}

\author{
Gurnal Rai Gandra Siregar ${ }^{1}$, Munar Lubis ${ }^{1}$, Isti Ilmiati Fujiati ${ }^{2}$ \\ ${ }^{I}$ Department of Pediatrics, Faculty of Medicine Universitas Sumatera Utara \\ ${ }^{2}$ Department of Public Health and Community Medicine, Faculty of Medicine, Universitas Sumatera Utara.
}

\begin{abstract}
World Health Organization (WHO) recommends to continue breastfeeding until two years of age. There are few studies assessing the correlation between breastfeeding duration and motor development. A cross-sectional study was conducted in April 2016 in Muara Batang Gadis District. The sample were children 3-6 years of age. Breastfeeding duration was obtained by interview, and motor development was assessed using Denver Developmental Screening Test II. Chi-square test was used to evaluate the correlation between breastfeeding duration and motor development, with P-value $<0.05$ and $95 \%$ Confidence Interval (CI). Among 204 children, 5.4\% had the fine motor delay, and 1\% had the gross motor delay. Children with breastfeeding duration for at least for two years had better fine motor development compared to breastfeeding duration for less than two years $(\mathrm{P}<0.001, \mathrm{PR}=1.139,95 \% \mathrm{CI}=1.055-1.231)$ and there is no difference in gross motor development $(\mathrm{P}=0.193, \mathrm{PR}=1.023,95 \% \mathrm{CI}=0.991-1.055)$. There is a correlation between breastfeeding duration and fine motor development.
\end{abstract}

Keyword: Breastfeeding, Motor Development, Denver Developmental Screening Test II Received 13 May 2018 | Revised 25 June 2018 | Accepted 18 September 2018

*Corresponding author at: Faculty of Medicine, Jalan Doktor Mansyur No.5 Kampus USU Padang Bulan, Medan, Sumatera Utara 20155 


\section{Introduction}

Breast milk is the best source of infant nutrient for optimal growth and development. World Health Organization (WHO) and The American Academy of Pediatrics (AAP) reaffirm their recommendation of exclusive breastfeeding for about six months, with the continuation of breastfeeding for one year or longer as mutually desired by mother and infant $[1,2]$.

The benefit of breastfeeding in infant growth and development will be increased if given in longer duration [3-5]. Studies have shown positive effect of longer duration of breastfeeding on a motor and cognitive development in childhood using Denver Developmental Screening Test II (Denver II) [6-8]. Chiu has examined the relationship between breastfeeding duration and four developmental domains: gross motor, fine motor, language and social skills which showed significant results that children who were breastfed for longer than six months had a lower risk of developmental delay. Their study showed that breastfeeding could protect the children from having developmental delay [8]. This study aims to determine the correlation between breastfeeding duration and motor development using Denver II.

\section{Methodology}

This cross-sectional study included 204 samples, aged 3-6 years old, without any history of current illness, severe malnutrition and perinatal problems. It was conducted in April 2016 in Singkuang, Batu Mundom, and Sikapas Village, Muara Batang Gadis District. Characteristics of the study subjects were also recorded, which included sex, age, head circumference, birth weight, weight and height. All subjects were interviewed, performed the physical examination, motor function and Denver II screening. Breastfeeding duration data was obtained by interview, and motor development was assessed using Denver II.

To evaluate the characteristic difference of the sample based on breastfeeding duration, we used independent T-test. Chi-square test was used to evaluate the correlation between breastfeeding and 95\% Confidence Interval (CI) was considered significant. Ethical research was confirmed by Research Ethic Committee, Medical Faculty, University of Sumatera Utara

\section{Results}

A sample of 204 children consisting of 108 boys and 96 girls were recruited. Demographic characteristics based on breastfeeding duration are presented in Table 1. 
Table 1. Difference Between Breastfeeding Duration Groups

\begin{tabular}{|c|c|c|c|}
\hline \multirow[t]{2}{*}{ Sample characteristics } & \multicolumn{2}{|c|}{ Breastfeeding duration } & \multirow[t]{2}{*}{$\mathrm{P}$} \\
\hline & $<2$ years & $\geq 2$ years & \\
\hline Sex, $n$ & & & $0.031 *$ \\
\hline Male & 40.0 & 68.0 & \\
\hline Female & 50.0 & 46.0 & \\
\hline Age (years), mean (SD) & $4.7(1.10)$ & $4.6(1.15)$ & 0.627 \\
\hline Nutritional status, $\mathrm{n}$ & & & 0.381 \\
\hline Underweight & 51.0 & 50.0 & \\
\hline Normoweight & 36.0 & 63.0 & \\
\hline Overweight & 2.0 & 1.0 & \\
\hline Obesity & 1.0 & 0.0 & \\
\hline $\begin{array}{l}\text { Head circumference }(\mathrm{cm}) \text {, } \\
\text { Mean (SD) }\end{array}$ & $49.1(0.81)$ & $49.3(0.98)$ & 0.085 \\
\hline $\begin{array}{l}\text { Birth weight (gram), } \\
\text { mean (SD) }\end{array}$ & $\begin{array}{l}2890.68 \\
(225.96)\end{array}$ & $\begin{array}{r}2817.1 \\
(208.01)\end{array}$ & $0.013^{*}$ \\
\hline
\end{tabular}

*Independent T-test

Among 204 children, 11 (5.39\%) children had the fine motor delay, and 193 children had normal fine motor development. All sample who had fine motor delay were children who were breastfed for less than two years, while among 193 samples which had normal fine motor development, 79 were breastfed for less than two years and 114 samples were breastfed for at least two years.

Statistical analysis showed that breastfeeding duration for at least two years was a protective factor for fine motor development $(\mathrm{PR}=1.139 ; 95 \% \mathrm{CI}=1.055-1.231)$. The correlation between breastfeeding duration and fine motor development is shown in Table 2.

Table 2. Correlation Between Breastfeeding Duration And Fine Motor Development

\begin{tabular}{|c|c|c|c|c|c|c|c|}
\hline & & \multicolumn{3}{|c|}{ Fine motor } & \multirow[t]{2}{*}{$\mathrm{P}$} & \multirow[t]{2}{*}{ PR } & \multirow{2}{*}{$\begin{array}{l}95 \% \\
\text { CI }\end{array}$} \\
\hline & & Normal & Delayed & Total & & & \\
\hline $\begin{array}{l}\text { Breastfeeding } \\
\text { Duration } \\
\text { (years) }\end{array}$ & $\geq 2$ & 14 & 0 & 114 & $<0.001^{*}$ & 1.139 & $\begin{array}{c}1.055 \\
- \\
1.231\end{array}$ \\
\hline Total & $<2$ & $\begin{array}{c}79 \\
193\end{array}$ & $\begin{array}{l}11 \\
11\end{array}$ & $\begin{array}{c}90 \\
204\end{array}$ & & & \\
\hline
\end{tabular}

*Chi-square $\mathrm{t}$

Among 204 children, two children had the gross motor delay, and 202 children had normal gross motor development. There is no correlation between breastfeeding duration and gross motor delay $(\mathrm{p}=0.193)$, two samples which had gross motor delay were breastfed for less than two years, while among 202 samples who had normal gross motor development, 88 were breastfed for less than two years and 114 were breastfed for at least two years. The correlation between breastfeeding duration and gross motor development is shown in Table 3. 
Tabel 3. Correlation Between Breastfeeding Duration And Gross Motor Development

\begin{tabular}{|c|c|c|c|c|c|c|c|}
\hline & & \multicolumn{2}{|c|}{ Gross motor } & & \multirow[t]{2}{*}{$\mathrm{P}$} & \multirow[t]{2}{*}{ PR } & \multirow[t]{2}{*}{$95 \% \mathrm{CI}$} \\
\hline & & Normal & Delayed & Total & & & \\
\hline \multirow{2}{*}{$\begin{array}{c}\text { Breastfeeding } \\
\text { Duration } \\
\text { (years) }\end{array}$} & $\geq 2$ & 114 & 0 & 114 & \multirow[t]{3}{*}{0.193} & \multirow[t]{3}{*}{1.023} & 0.991 \\
\hline & $<2$ & 88 & 2 & 90 & & & \\
\hline Total & & 202 & 2 & 204 & & & \\
\hline
\end{tabular}

\section{Discussion}

There is a correlation between breastfeeding duration and fine motor development $(\mathrm{p}<0.001)$. Breastfeeding duration for at least two years is associated with better fine motor development. Breastfeeding duration for at least two years was a protective factor for fine motor development $(\mathrm{PR}=1.139 ; 95 \% \mathrm{CI}=1.055-1.231)$.

A study by Oddy with 2868 samples, showed that infants who had been breastfed for four months or longer had significantly higher fine motor skills at age 1 and 3 , and did not show the correlation between breastfeeding duration with gross motor development [9]. Our results were in concordance with those findings.

This study correlates with a study by Sacker which showed that infants who were never breastfed exclusively, at least had at least a $40 \%$ greater likelihood of fine motor delay than infants who were given breast milk for a prolonged periods. However, contrasting with the study which showed that infants who had never been breastfed were $50 \%$ more likely to have the gross motor delay than infants who had been breastfed exclusively for at least four months. Infants who had never been breastfed were $30 \%$ more likely to have the gross motor delay than infants who were given some breast milk for up to 2 months [7]. We did not find the correlation between breastfeeding duration and gross motor development.

This study also showed similar results with a study by Chiu which stated that the protection against developmental delay remained significant for those children who were breastfed for more than six months. Children who were breastfed for longer than six months had a lower risk of developmental delay than those who were never breastfed [8].

A study by Dee in 10-71 months of age sample showed the result in infants that never been the breastfed group, $6 \%$ had the fine motor delay [10]. As in this study, we used the similar range of age sample groups, and we found a similar result.

A study by Ching in 2-3 years of age children included 2490 samples, showed results that breastfed infants were able to walk and produce meaningful words earlier than their counterparts. The association was more obvious and significant with increasing duration of breastfeeding in 
infants. This positive association was not altered by adjustment of numerous confounders [11].

The results suggest breastfeeding by itself enhanced neurodevelopment.

A study by Levantakou showed results that longer duration of breastfeeding was associated with increased scores in cognitive, language and motor development at 18 months of age [12]. We found the similar result with this study in motor development domain. However, we did not evaluate the other development domains.

The contrasting results of other studies about the correlation between breastfeeding duration and motor development can be due to other factors that can affect the children development process.

The statement about the benefit of breast milk and children development need more study with better design and adjustment for other confounding factors that can affect the children growth development.

\section{REFERENCES}

[1] W.H. Organization, Infant and young child feeding: model chapter for textbooks for medical students and allied health professionals., Infant and Young Child Feeding: Model Chapter for Textbooks for Medical Students and Allied Health Professionals. (2009).

[2] A.I. Eidelman, R.J. Schanler, M. Johnston, S. Landers, L. Noble, K. Szucs, L. Viehmann, Breastfeeding and the use of human milk, Pediatrics. 129 (2012) e827-e841.

[3] W.H. Oddy, J. Li, A.J. Whitehouse, S.R. Zubrick, E. Malacova, Breastfeeding duration and academic achievement at 10 years, Pediatrics. (2010) peds-2009.

[4] K.M. Clark, M. Castillo, A. Calatroni, T. Walter, M. Cayazzo, P. Pino, B. Lozoff, Breastfeeding and mental and motor development at 5\$1/2\$ years, Ambulatory Pediatrics. 6 (2006) 65-71.

[5] H. Bernardo, V. Cesar, W.H. Organization, Long-term effects of breastfeeding: a systematic review, (2013).

[6] O.H. Jonsdottir, I. Thorsdottir, G. Gunnlaugsson, M.S. Fewtrell, P.L. Hibberd, R.E. Kleinman, Exclusive breastfeeding and developmental and behavioral status in early childhood, Nutrients. 5 (2013) 4414-4428.

[7] A. Sacker, M.A. Quigley, Y.J. Kelly, Breastfeeding and developmental delay: findings from the millennium cohort study, Pediatrics. 118 (2006) e682-e689.

[8] W.-C. Chiu, H.-F. Liao, P.-J. Chang, P.-C. Chen, Y.C. Chen, Duration of breast feeding and risk of developmental delay in Taiwanese children: a nationwide birth cohort study, Paediatric and Perinatal Epidemiology. 25 (2011) 519-527.

[9] W.H. Oddy, M. Robinson, G.E. Kendall, J. Li, S.R. Zubrick, F.J. Stanley, Breastfeeding and early child development: a prospective cohort study, Acta Paediatrica. 100 (2011) 992-999.

[10] D.L. Dee, R. Li, L.-C. Lee, L.M. Grummer-Strawn, Associations between breastfeeding practices and young children's language and motor skill development, Pediatrics. 119 (2007) S92-S98.

[11] C. Li, Association between breastfeeding and developmental milestones in Chinese infants, HKU Theses Online (HKUTO). (2004).

[12] V. Leventakou, T. Roumeliotaki, K. Koutra, M. Vassilaki, E. Mantzouranis, P. Bitsios, M. Kogevinas, L. Chatzi, Breastfeeding duration and cognitive, language and motor development at 18 months of age: Rhea mother-child cohort in Crete, Greece, J Epidemiol Community Health. (2013) jech-2013. 